\title{
Mitigation of salt stress in white clover (Trifolium repens) by Azospirillum brasilense and its inoculation effect
}

\author{
Muhammad Khalid ${ }^{1}$ (D, Muhammad Bilal ${ }^{2}$, Danial Hassani ${ }^{1}$, Hafiz M. N. Iqbal ${ }^{3}$, Hang Wang ${ }^{4}$ and \\ Danfeng Huang ${ }^{1 *}$
}

\begin{abstract}
Background: Salinity is one of the increasingly serious environmental problems worldwide for cultivating agricultural crops. The present study was aimed to ascertain the potential of beneficial soil bacterium Azospirillum brasilense to alleviate saline stress in Trifolium repens. Experimental plants (white clover) were grown from seeds and inoculated with or without $A$. brasilense bacterial strain supplemented with $0,40,80$, or $120 \mathrm{mM} \mathrm{NaCl}$ into soil.

Results: The growth attributes including, shoot heights, root lengths, fresh and dry weights, leaf area and chlorophyll content were significantly enhanced in T. repens plants grown in A. brasilense inoculated soil than un-inoculated controls, particularly under elevated salinity conditions (40,80 and $120 \mathrm{mM} \mathrm{NaCl})$. Malondialdehyde content of leaf was recorded to be declined under saline conditions. Moreover, the $\mathrm{K}^{+} / \mathrm{Na}^{+}$ratio was also improved in bacteriuminoculated plants, since $A$. brasilense significantly reduced the root and shoot $\mathrm{Na}^{+}$level under high salty environment.

Conclusions: Results revealed that soil inoculation with A. brasilense could significantly promote T. repens growth under both non-saline and saline environments, and this study might be extended to other vegetables and crops for the germination and growth enhancement.
\end{abstract}

Keywords: Salinity, Leaf physiology, Stem physiology, Salinity stress, $\mathrm{K}^{+} / \mathrm{Na}^{+}$ratio

\section{Background}

Soil salinity is considered to be the most brutal environmental factor which caused a reduction in plant growth and crops productivity (Allakhverdiev et al. 2000). Cultivated soils all over the world are becoming more saline due to continuing use of poor quality water for irrigation, excessive fertilization, and desertification processes (Ramadoss et al. 2013). Currently, more than $20 \%$ of the worlds (26\% of Pakistan) agricultural irrigated land is affected by levels of salt that could markedly downscale the net agriculture yield (Munns and Tester 2008).

\footnotetext{
*Correspondence: hdf@sjtu.edu.cn

1 School of Agriculture and Biology, Shanghai Jiao Tong University, Shanghai 200240, China ${ }^{3}$ School of Engineering and Science, Tecnologico de Monterrey, Campus Monterrey, Ave. Eugenio Garza Sada 2501, Monterrey, N.L. 64849, Mexico

Full list of author information is available at the end of the article
}

Excessive salt concentration augments the $\mathrm{Na}^{+}$and $\mathrm{Cl}^{-}$ ions level in different plants that negatively affect the plant survival by disrupting different plant metabolisms, cellular homeostasis, and uncoupling major biochemical as well as physiological processes (Mahajan and Tuteja 2005). Although both $\mathrm{Na}^{+}$and $\mathrm{Cl}^{-}$ions have the capability to induce many physiological and/biochemical disorders in plants, nevertheless, $\mathrm{Cl}^{-}$is among the most hazardous (Tavakkoli et al. 2010).

Effective strategies for alleviating salinity stress involve developing salt-tolerant cultivars, in situ soil flushing, leaching excess soluble salts from upper to lower soil depths, reducing salt by collecting salt-accumulating aerial plant parts, and improvement of alkaline soils under cropping and leaching (Bacilio et al. 2004). Inoculation of crop with plant growth promoting bacteria (PGPB) is becoming more imperative as an alternative to mitigate abiotic stresses (i.e., salinity) since PGPB have been 
reported to overcome stress effects. Further, the beneficial properties of microbes under salinity has been attributed to the hydraulic conductivity, sequestering toxic $\mathrm{Na}^{+}$ions, osmolyte accumulation, retaining higher stomatal conductance and photosynthetic activities (Dodd and Pérez-Alfocea 2012).

PGPB are a diverse group of bacteria that possess the remarkable capability to promote growth and yield of many crops and wild plants (de-Bashan et al. 2012). Several species of PGPB, particularly species of the genus Azospirillum, Pseudomonas, and Arbuscular mycorrhizal fungi can effectively alleviate salt stress in plants (Fasciglione et al. 2015). Among PGPB, Azospirillum spp. is the most investigated bacterium because of its potential to colonize a wide-range vegetable crops and to enhance the general plant performance under normal or stressed environment. Indeed, it has been reported that inoculation mitigated the undesirable effects of $\mathrm{NaCl}$ on wheat seedlings with Azospirillum brasilense. The benefits of Azospirillum inoculation have also been observed in chickpea irrigated with saline water (Hamaoui et al. 2001). These favorable effects of the Azospirillum strains might be attributed to the secretion of several types of phytohormones in the surroundings of the roots. These phytohormones are physiologically active and hence, potentially assist the plants to propagate in stress conditions (Fasciglione et al. 2015).

Trifolium repens, the white clover, has been considered an important forage crop throughout the world. T. repens is also deliberated as a folk medicine in India against intestinal helminthic worms, and an in vivo experimental study corroborated that its aerial shoots possess unique anti-custodial properties (Tangpu et al. 2005). Like several other forage crops, $T$. repens is susceptible to salinity stress; reducing its growth and number of root nodules, and as a consequence, nitrogen fixation, as well as soil fertility level, is compromised (Acharya et al. 2011). The present work was carried out to evaluate $A$. brassilence potential for growth promotion and salinity resistance in white clover.

\section{Methods}

\section{Bacterial strain and growth conditions}

Bacterial strain, A. brasilense was provided by "The Leibniz Institute DSMZ-German Collection of Microorganisms and Cell Cultures". The strain was streaked in Lauria-Bertani (LB) agar plates and incubated at $30 \pm 0.2{ }^{\circ} \mathrm{C}$ for $24 \mathrm{~h}$. From LB agar plates, the bacterial cells were then transferred into LB-broth and cultured at $30 \pm 0.2^{\circ} \mathrm{C}$ under an agitation speed of $250 \mathrm{rpm}$ to obtain $1.0 \times 10^{9}$ colony-forming units $(\mathrm{CFU}) / \mathrm{mL}$.

\section{Seed treatment and germination experiment}

The healthy and mature seeds of $T$. repens were cleaned and disinfected with $3.5 \%$ sodium hypochlorite $(\mathrm{NaClO})$ solution for 1 min followed by soaking in $70 \%$ ethanol for $10 \mathrm{~min}$, and finally washed with distilled water for further use. Pre-sterilized plastic pots (20 cm diameter) comprising $800 \mathrm{~g}$ of soil were used to germinate the seeds by watering with Hoagland's solution $(400 \mathrm{~mL})$, which contained $\mathrm{NH}_{4} \mathrm{H}_{2} \mathrm{PO}_{4}, 1 \mathrm{mM}$; $\mathrm{KNO}_{3}, 5 \mathrm{mM} ; \mathrm{MgSO}_{4}, 0.5 \mathrm{mM}$; Fe-citrate, $60 \mu \mathrm{M}$; $\mathrm{Ca}\left(\mathrm{NO}_{3}\right)_{2}, 0.5 \mathrm{mM} ; \mathrm{MnCl}_{2} \cdot 4 \mathrm{H}_{2} \mathrm{O}, 18 \mu \mathrm{M} ; \mathrm{H}_{3} \mathrm{BO}_{3}$, $92 \mu \mathrm{M} ; \mathrm{CuSO}_{4} \cdot 5 \mathrm{H}_{2} \mathrm{O}, 0.6 \mu \mathrm{M} ; \mathrm{ZnSO}_{4} \cdot 7 \mathrm{H}_{2} \mathrm{O}, 1.6 \mu \mathrm{M}$ and $\left(\mathrm{NH}_{4}\right)_{6} \mathrm{Mo}_{7} \mathrm{O}_{24} \cdot 4 \mathrm{H}_{2} \mathrm{O}, 0.7 \mu \mathrm{M}$. After germination, Three uniform seedlings per pot were selected for continued growth and were treated with $1 \mathrm{~mL}$ bacterial suspension $\left(1.0 \times 10^{9} \mathrm{CFU} / \mathrm{mL}\right)$, per plant as inoculation treatment. The seedlings treated with $1.0 \mathrm{~mL}$ liquid LB medium were considered as control. For salt stress treatments, the seedlings were watered with Hoagland's nutrient solution supplemented with $0,40,80,120 \mathrm{mM} \mathrm{NaCl}$. Three plastic pots (Three plants/pot) were used as replications for each treatment. Plants were grown under controlled conditions at $28{ }^{\circ} \mathrm{C}$ during the day and $16{ }^{\circ} \mathrm{C}$ at night, irrigated daily through dropper with deionized water to maintain the moisture approximately at $60 \%$ water holding capacity of the soil, efforts were made to protect the leaching of salt and all pots were randomly placed in a greenhouse.

\section{Physiological measurements}

The plants were harvested after 60 days to determine physiological index and growth measurements including, leaf area and a whole number of leaves per plant. Measurement of leaf area was made through portable leaf area meter (Model YMJ-A, China). Leaf area/plant was divided by some leaves/plant to calculate the average leaf area. Once the plants were separated from pots, the growth parameters such as root and shoot lengths $(\mathrm{cm})$ were measured by a ruler. Shoot fresh weight $(\mathrm{g})$ was determined immediately, whereas the plant parts were oven-dried at $75{ }^{\circ} \mathrm{C}$ for 2-days after rinsing with deionized water for quantitative analysis of dry weights (g). Leaf chlorophyll content was analyzed following the reported method (Porra et al. 1989). Briefly, 80\% acetone was used to pulverize fresh leaves sample and centrifuged at $4{ }^{\circ} \mathrm{C}$ for $10 \mathrm{~min}$ at $10,000 \mathrm{rpm}$. The clear supernatants, thus obtained, were collected and recording OD measured chlorophyll content at 645 and $663 \mathrm{~nm}$. Thiobarbituric acid (TBA) protocol was adopted to probe the oxidative stress using the biomarker malondialdehyde (MDA) (Bao et al. 2009). 


\section{Ionic analysis}

Ionic analysis $\left(\mathrm{Na}^{+}\right.$and $\left.\mathrm{K}^{+}\right)$was made using an atomic absorption spectrophotometer available in Instrumental analysis center, SJTU following the method described previously (Wang et al. 2007). Ice-chilled $\mathrm{CaCl}_{2}(20 \mathrm{mM})$ was used to wash the plant roots twice for $5 \mathrm{~min}$ to exchange cell wall bound $\mathrm{Na}^{+}$. Surface salts from the shoots were removed by rinsing it in deionized water and the sample parts (root, shoot) were oven dried at $70{ }^{\circ} \mathrm{C}$ for three days to calculate dry weights. Dried plant tissues were used for $\mathrm{Na}^{+}$and $\mathrm{K}^{+}$analysis. These ions were extracted from dried plant samples for $2 \mathrm{~h}$ at $90^{\circ} \mathrm{C}$ in $100 \mathrm{mM}$ acetic acid.

\section{Statistical analysis}

All the data such as growth measurements, physiological index, ion contents, and ratio were analyzed and reported with standard deviations and means of three replicates. The means and standard errors were computed for each treatment, and the SE values were displayed as Y-error bars in the figures. The collected data was subjected to analysis of variance (ANOVA) and treatment means were compared by Duncan's New Multiple Range Test (DMRT) at $\mathrm{P}<0.05$ using a computer-based statistical software package (IBM SPSS Statistics 21).

\section{Results}

\section{White clover growth (shoot height and root length)} improvement by A. brasilense

Azospirillum brasilense possessed beneficial effects on white clover cultivation by increasing its growth and decreasing the susceptibilities to different salt concentration. Under the non-saline condition, the shoot height was improved to $60.86 \%$ in comparison to media control, whereas the shoot height was significantly increased in $A$. brasilense inoculated plants than that of un-inoculated plants. The enhancement in shoot height was recorded to be $58.82,57.8$ and $70 \%$ at 40,80 , and $120 \mathrm{mM} \mathrm{NaCl}$ treatments, respectively (Fig. 1A). Compared with media control, the root length of inoculated plants was improved to $62.06 \%$ under non-saline condition. A. brasilense significantly increased the root length by $70.83,58.82$, and $63.63 \%$ under at experimental concentration of 40, 80, and $120 \mathrm{mM} \mathrm{NaCl}$, respectively (Fig. 1B).

\section{Biomass measurement}

Azospirillum brasilense inoculation led to increased biomass of the white clover in non-saline conditions and also alleviated the detrimental effect of different concentration of salts $(\mathrm{NaCl})$. The shoot fresh weight of inoculated white clover was found to be 2.1-folds higher in non-saline conditions as compared to similar medium control. In the same way, shoot fresh weight of experimental plants treated with 40, 80, and $120 \mathrm{mM}$ $\mathrm{NaCl}$ were increased to 2.66, 1.16-folds and 2.33-folds (Fig. 2A). In non-saline condition, shoot dry weight was recorded to be 4.2 -folds higher with respect to the control medium. While in inoculated plants, the salt stress was significantly alleviated by $A$. brasilense, and therefore, 3.0-, 5.3- and 1.6-folds improvement in shoot dry weight was observed as compared to un-inoculated ones (Fig. 2B). Inoculated plants root dry weight was assessed to be $0.57 \%$ higher in non-saline condition. Increases in dry weight of other samples were also significant and recorded to be $0.55 \%, 0.56$ and 0.6 -folds greater than uninoculated plants at 40,80,120 mM NaCl concentration (Fig. 2C). In conclusion, $A$. brasilense had a significant salinity stress relieving effect on the growth of plants under all the tested concentrations of $\mathrm{NaCl}$.

\section{Improvement in leaf number and area}

Azospirillum brasilense supported the growth of plants under abiotic (salt etc.) stress and plays a significant
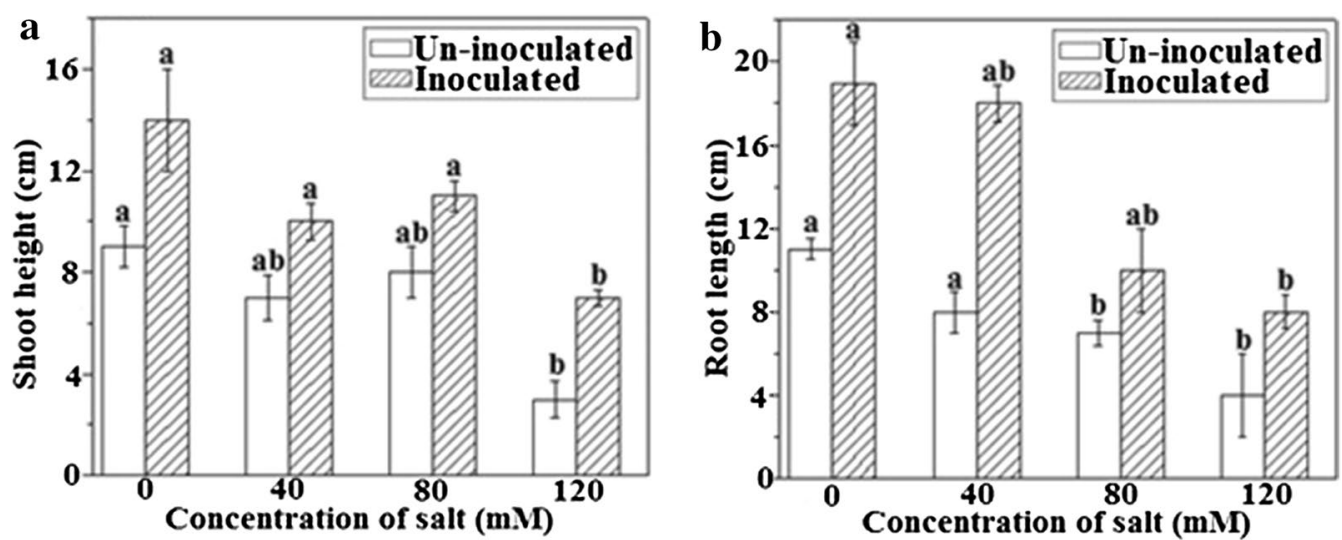

Fig. 1 Effects of $A$. brasilense inoculation on shoot height $(\mathbf{A})$ and root length $(\mathbf{B})$ of $T$. repens under varying concentrations of $\mathrm{NaCl}$ 

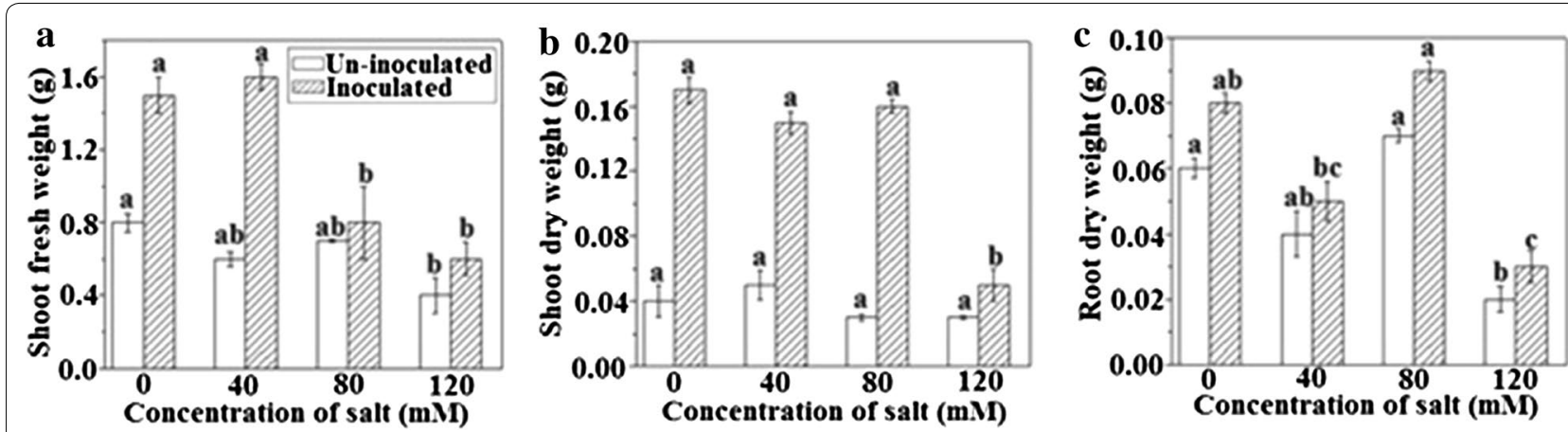

Fig. 2 Effects of A. brasilense inoculation on plant growth of T. repens under varying concentrations of $\mathrm{NaCl}$. A Shoot fresh weight, B shoot dry weight, $\mathbf{C}$ root dry weight

role in the development of leaves and chlorophyll in the absence as well as the presence of salinity stress. Leaf area of bacterial inoculated plants with no salt treatment was increased to 1.4-folds in contrast to equivalent uninoculated samples. Stress was alleviated in the rest of treatments by increasing the number of leaves to 2.27-, 1.25 - and 1.83 -folds relatively at $40,80,120 \mathrm{mM} \mathrm{NaCl}$ concentrations, correspondingly (Fig. 3A). Enhancement in some leaves per inoculated plant under non-saline condition was $54.5 \%$. While under $\mathrm{NaCl}$ treatment of 40 and $120 \mathrm{mM}$, leaf numbers were increased to 68.1 and 62.5 , respectively compared with un-inoculated plants samples. Nevertheless, this trend was observed to be contradicted for the plants treated with $80 \mathrm{mM} \mathrm{NaCl}$ concentration (Fig. 3B).

\section{Determination of chlorophyll content}

Besides increasing the number and area of leaves, $A$. brasilense also stimulated the amount of chlorophyll formation and supported its specific growth in bacterial inoculated plants. Leaf chlorophyll content in inoculated plants was increased to $61.5 \%$ in non-saline condition. Under appropriated saline condition, this ratio was 63.6, 75 and $0.62 \%$ grew at $\mathrm{NaCl}$ concentration of 40,80 , and $120 \mathrm{mM}$, accordingly (Fig. 4).

Measurement of leaf MDA, sodium and potassium content Lipid peroxidation is an index of membrane damage and/or permeability, and ions leakage occurred in salinity stress environments. The results showed that MDA content in plants inoculated by $A$. brasilense decreased significantly to $64.8 \%$ in non-salinity conditions and 24.1 , 20.90 and $27.5 \%$ in 40,80 , and $120 \mathrm{mM} \mathrm{NaCl}$ treatments, respectively. MDA biomarker assessment also demonstrated that $A$. brasilense could favorably regulate the oxidative stress and cell membrane integrity. The results from ion content analysis revealed that sodium content was remarkably reduced to $40 \%$ for non-saline conditions in plants treated with $A$. brasilense, whereas this ratio was 41.6, 46.66 and $43.33 \%$ increased for inoculated plants under 40, 80 and $120 \mathrm{mM} \mathrm{NaCl}$ level (Fig. 5A). Dry roots evaluation also showed that in all treatments
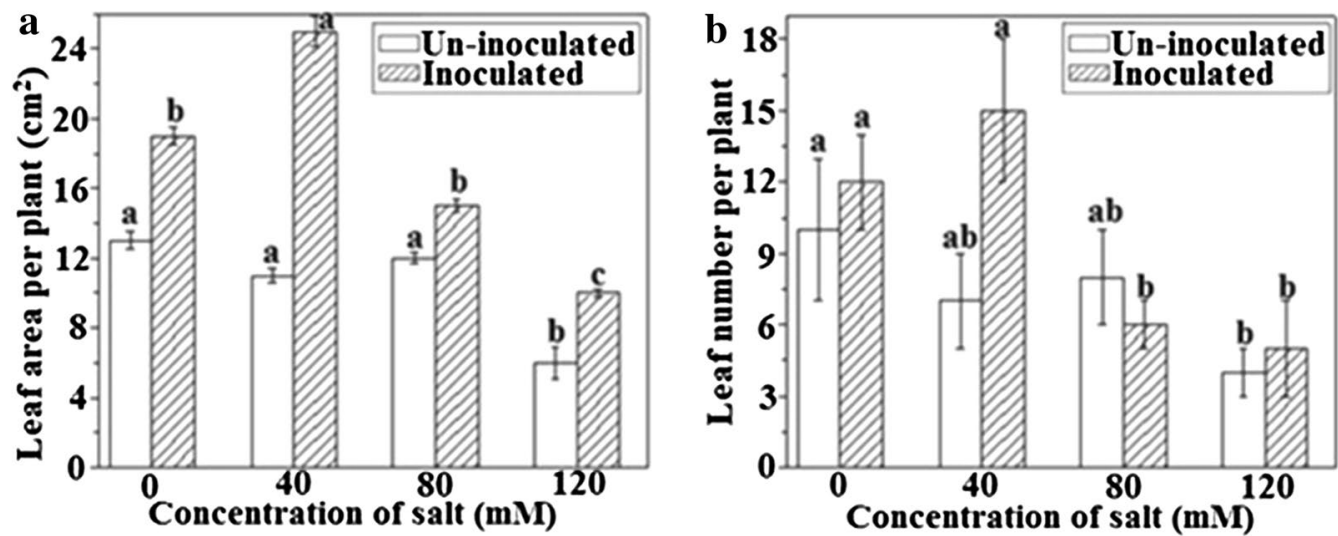

Fig. 3 Effects of A. brasilense inoculation on leaf development and growth of T. repens under various concentrations of $\mathrm{NaCl}$; A leaf area per plant, and $\mathbf{B}$ leaf number per plant 


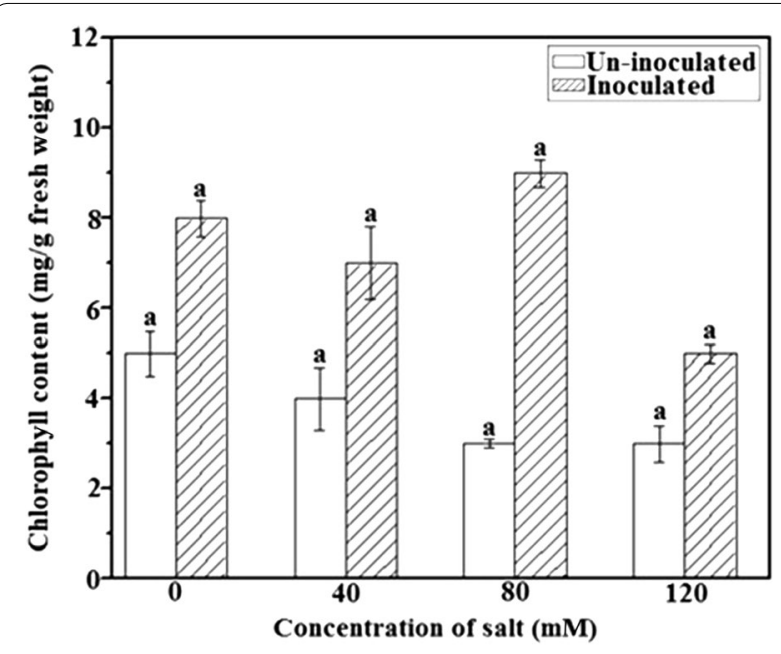

Fig. 4 Effects of A. brasilence inoculation on chlorophyll content of $T$. repens under different $\mathrm{NaCl}$ concentrations including $0,40,80,120 \mathrm{mM} \mathrm{mM} \mathrm{NaCl}$, the sodium content of inoculated plants decreased to $40,55.5,42.8$ and 41.1\% respectively (Fig. 5C). However, no significant reduction was recorded in potassium accumulation for all treatments (Fig. 5B, D).

\section{Discussion}

Salt stress negatively influences the morphological, ionic, and physiological as well as biochemical characteristics in plants (Chen et al. 2013; Abbasi et al. 2015). It has been reported that increasing the salt level, reduces the osmotic potential, which results in cell dehydration, due to increased water efflux from cell (Amjad et al. 2014). Beneficial soil bacterial mediated growth enhancing attributes have been documented in enormous plant species (Gray and Smith 2005; Xie et al. 2009; Paré et al. 2011). The growth amplification of several plants, such as wheat (Triticum aestivum), maize (Zea mays), tomato
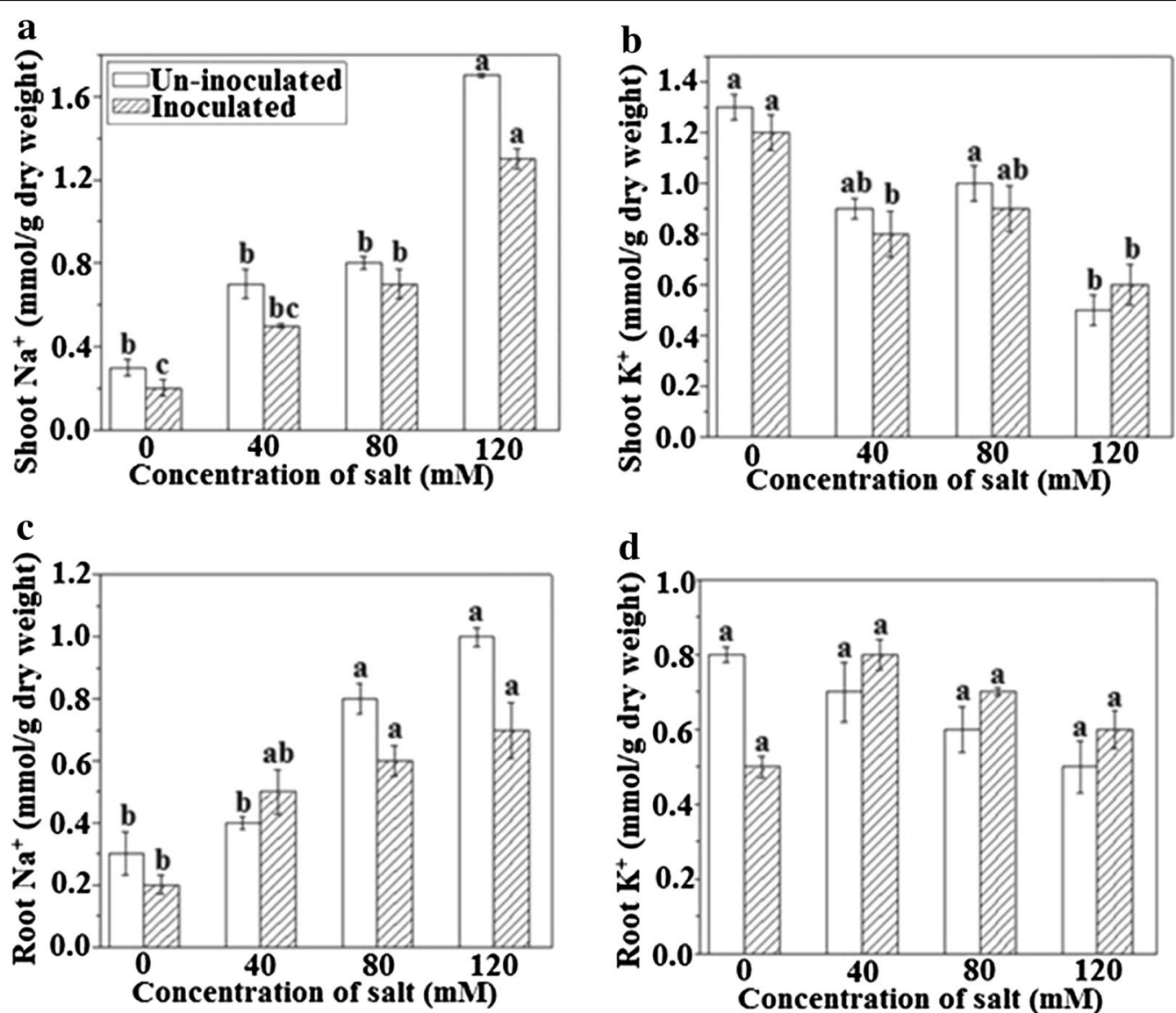

Fig. 5 Effects of $A$. brasilence inoculation on ion-contents of T. repens at varying concentrations of $\mathrm{NaCl} \mathbf{A}$ shoot $\mathrm{Na}^{+}$content, $\mathbf{B}$ shoot $\mathrm{K}^{+}$content, $\mathbf{C}$ root $\mathrm{Na}^{+}$content, $\mathbf{D}$ root $\mathrm{K}^{+}$content 
(Lycopersicon esculentum), dwarf salt wort (Salicornia bigelovii), chickpea (Cicer arietinum), and alfalfa (Medicago sativa) by beneficial soil bacteria have also been observed at varying salt exposures (Bashan et al. 2000; Mayak et al. 2004; Ibragimova et al. 2006; Bano and Fatima 2009; Tiwari et al. 2011). A significant growth improvement of white clover by $A$. brasilense inoculated soil recorded in the present study was comparable with previous reports in Arabidopsis (Zhang et al. 2007, 2008, Zhang et al. 2010a, b; Xie et al. 2009; Paré et al. 2011). Noticeably, our findings revealed that $A$. brasilense in white clover has more active shoot growth promoting role compared to its root growth, particularly under salt stress conditions $(40,80$, and $120 \mathrm{mM} \mathrm{NaCl}$ concentration). Similar results for salt preventing potentiality of Azospirillum strains have been documented previously by several researchers evaluated the bio-control and salt stress alleviating perspective of A. lipoferum in wheat crop and found that A. lipoferum displayed the good potential to promote the growth of wheat under saline conditions (up to $150 \mathrm{mM}$ of $\mathrm{NaCl}$ ) (Bashan and Levanony 1990). Synthesis of growth promoting substances (GPS) and adaptation to current environmental conditions may confer increased germination percentage and alleviation under prevailing salt conditions (RuedaPuente et al. 2007; Nadeem et al. 2013). Leaf development and/or enlargement play a significant role in plant production since it is strongly associated with plant growth and biomass accumulation (Gutiérrez-Boem and Thomas 1998; Bacilio et al. 2004; Battie-Laclau et al. 2013).

A significant augmentation in leaf area and leaf number per plant was also noted in $A$. brasilence inoculated white clover plants. In another study, Han et al. (2014) reported that GB03 inoculation significantly enlarged leaf area and number per plant, and thus average leaf area in white clover. Likewise, photosynthetic pigment, leaf chlorophyll content is also an important physiological/biological attribute directly related to photosynthesis rate in plants (Ma et al. 2012). Inoculation of $A$. brasilence considerably improved the leaf chlorophyll content in white clover plant, cultivated under both non-saline as well as variable salt concentrations of 40, 80, and $120 \mathrm{mM} \mathrm{NaCl}$. Similar to our study, Zhang et al. (2008) described that B. subtilis GB03 enhances photosynthetic efficiency by increasing chlorophyll content in Arabidopsis. In contrast, some reports highlighted that plants grown under salinity environments produced a smaller amount of chlorophyll and dry matter than those without salt exposure presumably due to chlorophyll per-oxidation (Lunde et al. 2007; Tuna et al. 2008; Barry 2009).

Soils with salinity contain an array of several cationanion pairs (i.e., $\mathrm{CaSO}_{4}, \mathrm{MgSO}_{4}, \mathrm{MgCl}_{2}, \mathrm{Na}_{2} \mathrm{CO}_{3}$, and
$\mathrm{Na}_{2} \mathrm{SO}_{4}$ ), with $\mathrm{Na}^{+}$ions being the predominant species (Zhang et al. 2010a). Growth is impeding, a common plant response to salt stress is often related to elevated intracellular $\mathrm{Na}^{+}$concentration and low $\mathrm{K}^{+} / \mathrm{Na}^{+}$ratio in the plant (Zhang et al. 2010a). Researchers have reported that plants grown under saline conditions can curtail sodium toxicity by limiting $\mathrm{Na}^{+}$uptake, re-directing $\mathrm{Na}^{+}$ from shoots to roots, and also extruding $\mathrm{Na}^{+}$loadings from root cells (Tester and Davenport 2003; Munns and Tester 2008; Zhang et al. 2010a, 2011; Kronzucker and Britto 2011). In a previous study, (Zhang et al. 2010a, b) reported that B. subtilis significantly reduced (54\%) the plant $\mathrm{Na}^{+}$content in Arabidopsis compared with control plants by down-regulating and up-regulating $H K T 1$ expression in roots and shoots, respectively. In this study, soil inoculated with $A$. brassilence considerably reduced the $\mathrm{Na}^{+}$level and increased $\mathrm{K}^{+}$to $\mathrm{Na}^{+}$ratio in both roots and shoots of the experimental plant at all levels of tested salt stresses.

\section{Conclusions}

In conclusion, the results revealed that soil inoculation with $A$. brasilense bacterium remarkably augments plant development and biomass of the tested plant (white clover) under both salted as well as non-salted settings. The present findings offer an opportunity for the application of this beneficial soil bacterium to cultivate different plants to combat saline toxicity. Further, comprehensive investigations elucidating the mechanisms by which bacteria elicit salt tolerance would be the focus of future studies.

\section{Authors' contributions \\ $\mathrm{MK}$, and $\mathrm{DH}$, performed the experiments, analyzed the data and wrote the paper; HW contributed in analytical analyses; MB, and HMNI contributed by analyzing the data, writing and reviewing the paper; $\mathrm{DH}$ provided financial support and supervised the project. All authors read and approved the final manuscript.}

\section{Author details \\ 1 School of Agriculture and Biology, Shanghai Jiao Tong University, Shang- hai 200240, China. ${ }^{2}$ State Key Laboratory of Microbial Metabolism, and School of Life Sciences and Biotechnology, Shanghai Jiao Tong University, Shang- hai 200240, China. ${ }^{3}$ School of Engineering and Science, Tecnologico de Monterrey, Campus Monterrey, Ave. Eugenio Garza Sada 2501, Monterrey, N.L. 64849, Mexico. ${ }^{4}$ Instrumental Analysis Center, Shanghai Jiao Tong University, Shanghai 200240, China.}

\section{Acknowledgements}

The authors are grateful to School of Agriculture and Biology, Shanghai Jiao Tong University, Shanghai 200240, China for providing experimental facilities. The technical and analytical help provided by Instrumental Analysis Center of SJTU is also thankfully acknowledged.

\section{Competing interests}

The authors declare that they have no competing interests.

Received: 21 November 2016 Accepted: 27 December 2016 Published online: 03 January 2017 


\section{References}

Abbasi GH, Akhtar J, Ahmad R, Jamil M, Anwar-ul-Haq M, Ali S, ljaz M (2015) Potassium application mitigates salt stress differentially at different growth stages in tolerant and sensitive maize hybrids. Plant Growth Regul 76:111-125

Acharya AR, Wofford DS, Kenworthy K, Quesenberry KH (2011) Combining ability analysis of resistance in white clover to southern root-knot nematode. Crop Sci 51:1928-1934

Allakhverdiev SI, Sakamoto A, Nishiyama Y, Inaba M, Murata N (2000) Ionic and osmotic effects of $\mathrm{NaCl}$-induced inactivation of photosystems I and II in Synechococcus sp. Plant Physiol 123:1047-1056

Amjad M, Akhtar J, Anwar-ul-Haq M, Yang A, Akhtar SS, Jacobsen SE (2014) Integrating role of ethylene and $\mathrm{ABA}$ in tomato plants adaptation to salt stress. Sci Hortic 172:109-116

Bacilio M, Rodriguez H, Moreno M, Hernandez JP, Bashan Y (2004) Mitigation of salt stress in wheat seedlings by a gfp-tagged Azospirillum lipoferum. Biol Fert Soil 40:188-193

Bano A, Fatima M (2009) Salt tolerance in Zea mays (L). following inoculation with Rhizobium and Pseudomonas. Biol Fertil Soil 45:405-413

Bao AK, Wang SM, Wu GQ, Xi JJ, Zhang JL, Wang CM (2009) Overexpression of the Arabidopsis $\mathrm{H}+$-PPase enhanced resistance to salt and drought stress in transgenic alfalfa (Medicago sativa L.). Plant Sci 176:232-240

Barry CS (2009) The stay-green revolution: recent progress in deciphering the mechanisms of chlorophyll degradation in higher plants. Plant Sci 176:325-333

Bashan Y, Levanony H (1990) Current status of Azospirillum inoculation technology: Azospirillum as a challenge for agriculture. Can J Microbiol 36:591-608

Bashan Y, Moreno M, Troyo E (2000) Growth promotion of the seawaterirrigated oilseed halophyte Salicornia bigelovii inoculated with mangrove rhizosphere bacteria and halotolerant Azospirillum spp. Biol Fertil Soil 32:265-272

Battie-Laclau P, Laclau JP, de Cassia Piccolo M, Arenque BC, Beri C, Mietton L, Ranger J (2013) Influence of potassium and sodium nutrition on leaf area components in Eucalyptus grandis trees. Plant Soil 371:19-35

Chen P, Wang H, Tang X, Brestic M, Shao H (2013) Comparative physiological study between cultivated and wild soybean species under salt stress. Jokull J 63:1-11

de-Bashan LE, Hernandez JP, Bashan Y (2012) The potential contribution of plant growth-promoting bacteria to reduce environmental degradation? A comprehensive evaluation. Appl Soil Ecol 61:171-189

Dodd IC, Pérez-Alfocea F (2012) Microbial amelioration of crop salinity stress. J Exp Bot 2012:Ers033

Fasciglione G, Casanovas EM, Quillehauquy V, Yommi AK, Goni MG, Roura SI, Barassi CA (2015) Azospirillum inoculation effects on growth, product quality and storage life of lettuce plants grown under salt stress. Sci Hortic 195:154-162

Gray E, Smith D (2005) Intracellular and extracellular PGPR: commonalities and distinctions in the plant-bacterium signaling processes. Soil Biol Biochem 37:395-412

Gutiérrez-Boem FH, Thomas GW (1998) Phosphorus nutrition affects wheat response to water deficit. Agron J 90:166-171

Hamaoui B, Abbadi JM, Burdman S, Rashid A, Sarig S, Okon Y (2001) Effects of inoculation with Azospirillum brasilense on chickpeas (Cicer arietinum) and faba beans (Vicia faba) under different growth conditions. Agronomie 21:553-560

Han QQ, Lü XP, Bai JP, Qiao Y, Paré PW, Wang SM, Wang ZL (2014) Beneficial soil bacterium Bacillus subtilis (GB03) augments salt tolerance of white clover. Front Plant Sci 5:525

Ibragimova MV, Rumyantseva ML, Onishchuk OP, Belova VS, Kurchak ON Andronov EE, Simarov BV (2006) Symbiosis between the root-nodule bacterium Sinorhizobium meliloti and alfalfa (Medicago sativa) under salinization conditions. Microbiology 75:77-81

Kronzucker HJ, Britto DT (2011) Sodium transport in plants: a critical review. New Phytol 189:54-81

Lunde C, Drew DP, Jacobs AK, Tester M (2007) Exclusion of $\mathrm{Na}^{+}$via sodium ATPase (PpENA1) ensures normal growth of Physcomitrella patens under moderate salt stress. Plant Physiol 144:1786-1796
Ma Q, Yue LJ, Zhang JL, Wu GQ, Bao AK, Wang SM (2012) Sodium chloride improves photosynthesis and water status in the succulent xerophyte Zygophyllum xanthoxylum. Tree Physiol 32:4-13

Mahajan S, Tuteja N (2005) Cold, salinity and drought stresses: an overview. Arch Biochem Biophys 444:139-158

Mayak S, Tirosh T, Glick BR (2004) Plant growth-promoting bacteria confer resistance in tomato plants to salt stress. Plant Physiol Biochem 42:565-572

Munns R, Tester M (2008) Mechanisms of salinity tolerance. Annu Rev Plant Biol 59:651-681

Nadeem SM, Zahir ZA, Naveed M, Nawaz S (2013) Mitigation of salinityinduced negative impact on the growth and yield of wheat by plant growth-promoting rhizobacteria in naturally saline conditions. Ann Microbiol 63:225-232

Paré PW, Zhang H, Aziz M, Xie X, Kim MS, Shen X, Zhang J (2011) Beneficial rhizobacteria induce plant growth: mapping signaling networks in Arabidopsis. In: Biocommunication in soil microorganisms. Springer, Berlin, pp 403-412

Porra R, Thompson W, Kriedemann P (1989) Determination of accurate extinction coefficients and simultaneous equations for assaying chlorophylls $a$ and $b$ extracted with four different solvents: verification of the concentration of chlorophyll standards by atomic absorption spectroscopy. Biochim Biophys Acta Bioenerg 975:384-394

Ramadoss D, Lakkineni VK, Bose P, Ali S, Annapurna K (2013) Mitigation of salt stress in wheat seedlings by halotolerant bacteria isolated from saline habitats. Springer Plus 2:1-7

Rueda-Puente EO, García-Hernández JL, Preciado-Rangel P, Murillo-Amador B, Tarazón-Herrera MA, Flores-Hernández A, Mwandemele O (2007) Germination of Salicornia bigelovii ecotypes under stressing conditions of temperature and salinity and ameliorative effects of plant growthpromoting bacteria. J Agron Crop Sci 193:167-176

Tangpu V, Temjenmongla K, Yadav AK (2005) Anticestodal activity of Trifolium repens. extract. Pharm Biol 42:656-658

Tavakkoli E, Rengasamy P, McDonald GK (2010) High concentrations of $\mathrm{Na}^{+}$ and $\mathrm{Cl}^{-}$ions in soil solution have simultaneous detrimental effects on growth of faba bean under salinity stress. J Exp Bot 2010:erq25

Tester M, Davenport R (2003) $\mathrm{Na}^{+}$tolerance and $\mathrm{Na}^{+}$transport in higher plants. Ann Bot 91:503-527

Tiwari S, Singh P, Tiwari R, Meena KK, Yandigeri M, Singh DP, Arora DK (2011) Salt-tolerant rhizobacteria-mediated induced tolerance in wheat (Triticum aestivum) and chemical diversity in rhizosphere enhance plant growth. Biol Fertil Soil 47:907-916

Tuna AL, Kaya C, Higgs D, Murillo-Amador B, Aydemir S, Girgin AR (2008) Silicon improves salinity tolerance in wheat plants. Environ Exp Bot 62:10-16

Wang S-M, Zhang J-L, Flowers TJ (2007) Low-affinity $\mathrm{Na}^{+}$uptake in the halophyte Suaeda maritima. Plant Physiol 145:559-571

Xie X, Zhang H, Pare P (2009) Sustained growth promotion in Arabidopsis with long-term exposure to the beneficial soil bacterium Bacillus subtilis (GB03). Plant Sig Behav 4:948-953

Zhang H, Kim MS, Krishnamachari V, Payton P, Sun Y, Grimson M, Paré PW (2007) Rhizobacterial volatile emissions regulate auxin homeostasis and cell expansion in Arabidopsis. Planta 226:839-851

Zhang H, Kim MS, Sun Y, Dowd SE, Shi H, Paré PW (2008) Soil bacteria confer plant salt tolerance by tissue-specific regulation of the sodium transporter HKT1. Mol Plant Microb Interact 21:737-744

Zhang H, Murzello C, Sun Y, Kim MS, Xie X, Jeter RM, Paré PW (2010a) Choline and osmotic-stress tolerance induced in Arabidopsis by the soil microbe Bacillus subtilis (GB03). Mol Plant Microb Interact 23:1097-1104

Zhang J-L, Flowers TJ, Wang S-M (2010b) Mechanisms of sodium uptake by roots of higher plants. Plant Soil 326:45-60

Zhang N, Wu K, He X, Li SQ, Zhang ZH, Shen B, Shen QR (2011) A new bioorganic fertilizer can effectively control banana wilt by strong colonization with Bacillus subtilis N11. Plant Soil 344:87-97 